\title{
EGF-induced trophoblast secretion of MMP-9 and TIMP-1 involves activation of both PI3K and MAPK signalling pathways
}

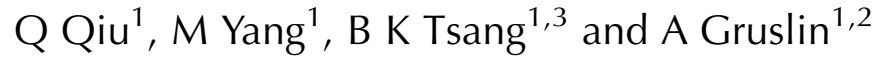

${ }^{1}$ Hormones, Growth and Development Program, Ottawa Health Research Institute, Ottawa, Ontario, Canada K1Y 4E9, Divisions of ${ }^{2}$ Maternal-Fetal Medicine and ${ }^{3}$ Reproductive Medicine, Department of Obstetrics and Gynaecology, University of Ottawa, The Ottawa Hospital, Ottawa, Ontario, Canada K1H 8L6

Correspondence should be addressed to A Gruslin; Email: agruslin@ottawahospital.on.ca

\begin{abstract}
Epidermal growth factor (EGF) is present in the maternal-fetal environment and has an important role in placental development. Matrix metalloproteinase-9 (MMP-9) expression/activation is a pre-requisite in extravillous trophoblast invasion. Whereas EGF up-regulates MMP-9 activity in a variety of cell types, there is no direct evidence for the stimulation of MMP-9 and tissue inhibitor of metalloproteinase-1 (TIMP-1) secretion by EGF in extravillous trophoblasts. In addition, the signalling pathways involved in this regulation are not clear. In the present study, we have examined the possible involvement of the phosphatidylinositol 3-kinase (PI3K) and mitogen-activated protein kinase (MAPK) pathways in the regulation of the MMP-9/TIMP-1 system by EGF in vitro. We used a well-established invasive extravillous trophoblast cell line (HTR8/Svneo) and measured gene and protein expression by semi-quantitative RT-PCR and western analysis respectively. MMP activity was determined by zymography. We showed for the first time that EGF activated both PI3K/Akt and MAPK/extracellular-signal regulated kinase (ERK) signalling in HTR8/SVneo, and increased both MMP-9 and TIMP-1 mRNAs and protein concentrations. Interfering with either signalling pathway via PI3K inhibitor LY294002 or MEK inhibitor U0126 in EGF-stimulated HTR8/SVneo cells blocked the induction of MMP-9 and TIMP-1. LY294002 inhibited Akt phosphorylation, but had no effect on ERK phosphorylation; U0126 suppressed ERK phosphorylation without interfering with the phosphorylation of Akt. In addition, expression of constitutively active Akt (Myr-Akt1, Myr-Akt2, Myr-Akt3) was not sufficient to induce proMMP-9 and TIMP-1 secretion. Our results suggest that the activation of both PI3K and MAPK pathways in extravillous trophoblasts is necessary for the up-regulation of MMP-9 and TIMP-1 expression by EGF.

Reproduction (2004) 128 355-363
\end{abstract}

\section{Introduction}

Matrix metalloproteinases (MMPs) are a family of neutral proteinases that catalyse the destruction of the extracellular matrix (ECM). Among the MMPs identified, MMP-9 (gelatinase B) appears to have an important role in a wide array of physiological and pathophysiological processes, including placental development, wound healing, angiogenesis, inflammation and tumour invasion/metastasis (Van den Steen et al. 2002). Degradation and reconstitution of ECM in uterine endometrium are required for trophoblast invasion and are regulated by MMPs (Roth \& Fisher 1999). In particular, MMP-9 is highly expressed by extravillous trophoblasts during trophoblast invasion in the first trimester of gestation (Behrendtsen et al. 1992). In in vitro studies, MMP-9 expression is crucial for trophoblast invasion into collagen gels. MMP-9 expression/activation is a pre-requisite and rate-limiting step in trophoblast invasion (Bischof et al. 2002, Campbell et al. 2003) and aberrant MMP-9 expression in extravillous trophoblasts is linked to preeclampsia, a disease characterized by poor trophoblast invasion (Kolben et al. 1996). MMP-9 knockout mice have impaired reproduction (Dubois et al. 2000). Thus studies of the mechanism regulating the expression of MMP-9 are important to an understanding of matrix degradation and extravillous trophoblast invasion.

MMP-9 secretion in invasive cytotrophoblasts is stimulated by interleukin (IL)-1 $\beta$ (Librach et al. 1994), tumour necrosis factor $\alpha$ (TNF $\alpha$ ) (Meisser et al. 1999), insulin-like growth factor binding protein (IGFBP)-1 (Bischof et al. 1998), leptin (Castellucci et al. 2000) and human chorionic gonadotropin (hCG) (Licht et al. 2001). In contrast, IL-10 (Roth \& Fisher 1999) and transforming growth factor $\beta$ (Meisser et al. 1999) are known to inhibit trophoblastic MMP-9 secretion. Epidermal growth factor (EGF)-induced MMP-9 secretion, believed to facilitate tumour invasion and metastasis, has been demonstrated in various tumour 
cells (Ellerbroek et al. 1998, Charoenrat et al. 2000, Cox et al. 2000, Liu \& Klominek 2003, Nutt et al. 2003). Although it has been shown that EGF stimulates trophoblast invasion (Bass et al. 1994), the influence of the growth factor on MMP-9 secretion by extravillous trophoblasts has not yet been reported.

Tissue inhibitors of metalloproteinases (TIMPs) are important regulators of MMP activity (Denhardt et al. 1993). Although several members of the TIMP family have been identified, proteolysis by MMP-9 is mostly regulated by the action of endogenous TIMP-1 (Itoh \& Nagase 1995). In addition, TIMP-1 is a multifunctional protein, known to be involved in the control of cell growth, differentiation and programmed cell death, independent of its influence on MMP-9 (Guedez et al. 1998, Li et al. 1999).

It is well established in various systems that EGF receptor (EGFR) ligation leads to activation of the phosphatidylinositol 3-kinase (PI3K) and mitogen-activated protein kinase (MAPK) pathways, resulting in the activation of several transcription factors. For instance, EGFR activates the $\mathrm{PI3K}$ and MAPK/extracellular-signal regulated kinase (ERK) pathways, which modulate the activation of $\mathrm{NF \kappa B}$ and AP-1 respectively, in human head and neck squamous cell carcinoma lines (Bancroft et al. 2002). Transcription factors Ets-1 and -2 are activated in response to EGF in human breast tumour cells (Watabe et al. 1998). It has also been demonstrated that regulatory elements of the transcription factors $\mathrm{AP}-1$, Ets and $\mathrm{NF \kappa B}$ are present in the promoter region of the MMP-9 gene (Huhtala et al. 1991), whereas the TIMP-1 promoter contains AP-1 and Ets binding sites (Borden \& Heller 1997). Therefore, we hypothesized that EGF induces MMP-9 and TIMP-1 secretion through activation of PI3K and MAPK signalling in extravillous trophoblasts.

In this paper, we investigated the effect of EGF on the secretion of MMP-9 and TIMP-1 and the signalling pathways involved in the regulation of MMP-9 and TIMP-1 by EGF in the invasive trophoblast cell line TR8/SVneo. We found that EGF up-regulated the secretion of both MMP-9 and TIMP-1. Using pharmacological inhibitors and molecular approaches, we have shown that both PI3K/Akt and MAPK/ERK signalling pathways are essential to the increase in trophoblast secretion of MMP-9 and TIMP-1 by EGF. We conclude that EGF-induced increases in MMP-9 and TIMP-1 secretion require the activation of both PI3K and MAPK signalling pathways.

\section{Materials and Methods}

\section{Cell lines and culture conditions}

The HTR-8/SVneo cells were a gift provided by $\mathrm{Dr}$ Charles H. Graham (Queen's University, Kingston, ON, Canada). This cell line was established from explant culture of first-trimester human placenta and immortalized by the simian virus 40 large $\mathrm{T}$ antigen (Graham et al. 1993). These cells exhibit a high proliferation index and share various phenotypic similarities with the parental HTR-8 cells, including in vitro invasive abilities. Cells $\left(6 \times 10^{5} /\right.$ well in six-well plates) were plated for $6 \mathrm{~h}$ in $1 \mathrm{ml} \mathrm{RPMI} 1640$ and $10 \%$ fetal bovine serum (FBS), first cultured overnight and subsequently incubated in fresh serum-free media containing EGF (Sigma) in various concentrations $(0,0.1,1,10,50 \mathrm{ng} / \mathrm{ml})$. In experiments with pharmacological inhibitors, inhibitors of PI3K (LY294002, $20 \mu \mathrm{mol} / \mathrm{l}$; Sigma) or of MAPK (U0126, $10 \mu \mathrm{mol} / \mathrm{l}$; Cell Signalling, Beverly, MA, USA) were dissolved in DMSO and added to each group $1 \mathrm{~h}$ before treatment with EGF $(10 \mathrm{ng} / \mathrm{ml}, 24 \mathrm{~h})$. Each experimental group received an equal amount of DMSO (1:1000; vehicle). Whole cell lysates were subjected to Western blot analysis to determine the content of the phosphorylated form of EGFR, Akt and ERK1/2. Conditioned media were collected after $24 \mathrm{~h}$ of treatment for determination of MMP-9 and MMP-2 activity (zymographic analysis) and of the content of TIMP-1 and TIMP-2 (Western blot analysis). Total RNA was isolated and TIMP-1 and the abundance of MMP-9 mRNAs was determined by semiquantitative RT-PCR.

\section{Western blot analysis}

At the end of the culture period, cells were washed with ice-cold PBS and lysed by sonication in lysis buffer $(50 \mathrm{mmol} / \mathrm{l}$ HEPES $(\mathrm{pH} 7.4), 150 \mathrm{mmol} / \mathrm{l} \mathrm{NaCl}, 1 \mathrm{mmol} / \mathrm{l}$ EGTA, $10 \mathrm{mmol} / \mathrm{I}$ sodium pyrophosphate, $1.5 \mathrm{mmol} / \mathrm{l}$ $\mathrm{MgCl}_{2}, 100 \mathrm{mmol} / \mathrm{l}$ sodium fluoride, $10 \%$ glycerol, $1 \%$ Triton $\mathrm{X}-100,1 \mathrm{mmol} / \mathrm{l}$ sodium orthovanadate, $1 \mathrm{mmol} / \mathrm{l}$ phenylmethylsuphonyl fluoride, $10 \mu \mathrm{g} / \mathrm{ml}$ aprotinin). Insoluble material was removed by centrifugation $(14000 \mathrm{~g}$, $4{ }^{\circ} \mathrm{C}, 20 \mathrm{~min}$ ) and the protein content in the supernatant was determined with the BioRad DC protein kit assay (BioRad). Aliquots of protein $(50 \mu \mathrm{g})$ were resolved by SDS-PAGE and electrotransferred to nitrocellulose membranes. The membranes were blocked $(1 \mathrm{~h}$, room temperature) in blotto (Tris-buffered saline at $\mathrm{pH} 7.6$ with $0.05 \%$ Tween 20 (TBS-T) and 5\% dehydrated non-fat milk). After rinsing with TBS-T, membranes were immunoblotted with antibodies to phospho-EGFR (Upstate, Lake Placid, NY, USA), phospho-Akt (Cell Signalling Technology Inc., Beverly, MA, USA), phospho-ERK1/2 (Cell Signalling), phospho-p70S6K $\left(\mathrm{Thr}^{389}\right.$ ) (Cell Signalling) or GAPDH (loading control; Abcam Ltd, Cambridge, UK). The conditioned medium, concentrated from $0.50 \mathrm{ml}$ to approximately $30 \mu \mathrm{l}$ with Microcon YM-3 (Millipore Corporation, Bedford, MA, USA), was resolved by SDS-PAGE under reducing conditions. Aliquots of $10 \mu \mathrm{g}$ protein were resolved by SDS-PAGE and electrotransferred to nitrocellulose membranes. The membranes were immunoblotted with antibodies to TIMP-1 and TIMP-2 (Chemicon, Temecula, CA, USA). The bands were visualized using ECL reagents and quantitated with Scion Image Software (Beta 4.0.2, Scion Corporation, Frederick, MA, USA). 


\section{Zymographic analysis}

The activities of MMP-9 and MMP-2 in the spent media were determined by zymography. Briefly, aliquots of the media containing $1 \mu \mathrm{g}$ protein were incubated $(10 \mathrm{~min}$, room temperature) with $1 / 3$ sample volume of loading buffer $(200 \mathrm{mmol} / \mathrm{l}$ Tris- $\mathrm{HCl}, 8 \%$ SDS, $0.04 \%$ bromophenol and $40 \%$ glycerol) and resolved on a $10 \%$ SDS polyacrylamide gel containing gelatin $(0.25 \mathrm{mg} / \mathrm{ml}$; Sigma). The gel was then washed $(2.5 \%$ Triton, $1 \mathrm{~h}$ with four changes of wash solution) to remove SDS and incubated $\left(36 \mathrm{~h}, 37^{\circ} \mathrm{C}\right)$ in a renaturating buffer $(50 \mathrm{mmol} / \mathrm{l}$ Tris $-\mathrm{HCl} \mathrm{pH} 7.5$, $10 \mathrm{mmol} / \mathrm{l} \mathrm{CaCl}_{2}, 150 \mathrm{mmol} / \mathrm{l} \mathrm{NaCl}$ and $0.02 \%$ sodium azide). Gels were stained with Coomassie brilliant blue and destained in methanol/acetic acid $(30 \% / 10 \% \mathrm{v} / \mathrm{v})$. Proteolytic activity was identified as a clear band on a blue background. The images were scanned and quantitative enzyme analysis was carried out using Scion Image Software.

\section{RNA isolation and semiquantitative RT-PCR analysis}

Total RNA was isolated with RNeasy Mini Kit (Qiagen) according to the manufacturer's instructions. Aliquots of $1 \mu \mathrm{g}$ total RNA were used for first strand cDNA synthesis in $20 \mu \mathrm{l}$ reaction volume with 200 units M-MLV reverse transcriptase (Invitrogen). The purity of the RNA preparations was confirmed by the absence of PCR product in the samples that had not undergone RT reaction. Primer pairs for CDNA amplification (in the $5^{\prime}-3^{\prime}$ direction) were as follows: GGATGGGAAGTACTGGCGATTC (forward) and CACTTGGTCCACCTGGTTCAAC (reverse) for human MMP-9; CGCTGACATCCGGTTCGTCTAC (forward) and GTGGACACTGTGCAGGCTTCAG (reverse) for human TIMP1; GGACTTCGAGCAAGAGATGG (forward) and CACCTTCACCGTTCCAGTTT (reverse) for human $\beta$-actin. The expected fragment lengths of MMP9, TIMP-1 and $\beta$-actin were 478,431 and $629 \mathrm{bp}$ respectively. After the linear range of PCR for each target gene had been determined, PCR amplification was performed on the Mastercycler (Brinkmann Instruments Inc., Westbury, New York, USA) using HotStarTaq DNA polymerase (Qiagen) for 25 cycles for TIMP-1 and $\beta$-actin and 40 cycles for MMP-9. HotStarTaq DNA polymerase was activated at $95^{\circ} \mathrm{C}$ for $15 \mathrm{~min}$ before the beginning of the cycle $\left(94^{\circ} \mathrm{C}\right.$ for $30 \mathrm{~s}$ for denaturing, $54^{\circ} \mathrm{C}$ for annealing and $72{ }^{\circ} \mathrm{C}$ for extension). PCR products on $2 \%$ agarose gels were stained with ethidium bromide and visualized under u.v. transillumination. The ratios of MMP-9 and TIMP-1 to $\beta$-actin were determined with the use of a computerized densitometric imager.

\section{Transient transfection}

The cells were plated overnight in RPMI 1640 and 10\% FBS. At $60-80 \%$ confluence, cells were transfected with constitutively active Akt1 (HA-Myr-Akt1-PCMV6), constitutively active Akt2 (HA-Myr-Akt2-pcDNA3.1), constitutively active Akt3 (HA-Myr-Akt3 $\Delta \mathrm{PH}-\mathrm{pcDNA3.1)}$ expression vectors (generously provided by Dr Jin Cheng, University of South Florida, Tampa, FL, USA) or control vectors (PCMV6 and pcDNA 3.1) separately, using Effectene Transfection Reagent (Qiagen) and according to the manufacturer's instructions. After incubation for $6 \mathrm{~h}$, cells were washed and incubated in serum-free media for $18 \mathrm{~h}$.

\section{Statistical analyses}

All experiments were performed at least three times, and values are given as the mean \pm S.E. Data were analysed by ANOVA and Newman-Keul's multiple comparison tests. The level of significance was set at $P<0.05$.

\section{Results}

\section{Effect of EGF and inhibitors of PI3K and MAPK on phospho-EGFR, phospho-Akt and phospho-ERK1/2 contents}

EGF treatment $(10 \mathrm{ng} / \mathrm{ml})$ increased phospho-EGFR, phospho-Akt and phospho-ERK1/2 contents in HTR8/SVneo cells within $15 \mathrm{~min}$ of treatment (Fig. 1). Addition of the PI3K inhibitor LY $294002(20 \mu \mathrm{mol} / \mathrm{l}) 1 \mathrm{~h}$ before EGF treatment had no effect on phospho-ERK content, but completely suppressed the EGF-induced increase in phospho-Akt content. In contrast, the MAPK inhibitor U0126 (10 $\mu \mathrm{mol} / \mathrm{l})$ was ineffective with respect to phospho-Akt content, but markedly suppressed the increase in phospho-ERK content induced by the growth factor. The presence of both inhibitors attenuated increases in both phospho-Akt and phospho-ERK1/2 contents (Fig. 1). The increased phosphoEGFR content in response to EGF treatment was not affected by the presence of the inhibitors (Fig. 1). Taken together, these findings demonstrate that, under the current

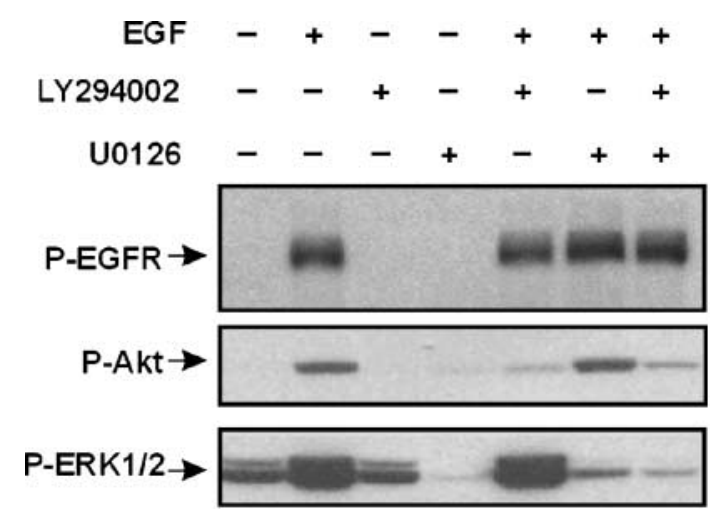

Figure 1 Effect of EGF on phospho-EGFR (P-EGFR), phospho-Akt (P-Akt) and phospho-ERK1/2 (P-ERK1/2) contents in the absence or presence of LY294002 or U0126. HTR8/SVneo cells were starved in serum-free medium overnight and treated with EGF $(10 \mathrm{ng} / \mathrm{ml})$ for $15 \mathrm{~min}$. LY294002 (20 $\mu \mathrm{mol} / \mathrm{l})$ and U0126 $(10 \mu \mathrm{mol} / \mathrm{l})$ were added $1 \mathrm{~h}$ before EGF treatment where indicated in the figure. Whole cell lysates were used for immunoblotting assay to detect P-EGFR, P-Akt and P-ERK1/2. 
experimental conditions, the effect of the inhibitors were indeed specific to the signalling pathways concerned.

\section{Possible involvement of PI3K and MAPK in the regulation of MMP-9 and TIMP-1 MRNA abundance}

To define the possible regulatory role of EGF on MMP-9 and TIMP-1 mRNA levels, the trophoblast cells were cultured for $24 \mathrm{~h}$ with various concentrations of $\operatorname{EGF}(0,0.1$, $1,10,50 \mathrm{ng} / \mathrm{ml}$ ). As seen in Fig. 2A, EGF increased the abundance of MMP-9 (478 bp) and TIMP-1 (431 bp) mRNAs in trophoblast cells in a concentration-dependent manner and observable increases were evident at $10 \mathrm{ng} / \mathrm{ml}$ or more. In order to examine the involvement of $\mathrm{PI} 3 \mathrm{~K}$ and MAPK signalling in up-regulating the abundance of MMP-9 and TIMP-1 mRNAs, cells were treated with EGF $(10 \mathrm{ng} / \mathrm{ml})$ for $24 \mathrm{~h}$ with or without $1 \mathrm{~h}$ pre-treatment with LY294002 $(20 \mu \mathrm{mol} / \mathrm{l})$ or U0126 $(10 \mu \mathrm{mol} / \mathrm{l})$, or both. The increases in mRNA abundance for TIMP-1 and MMP9 elicited by the growth factor were inhibited in the presence of LY294002 or U0126, or both (Fig. 2B).

A

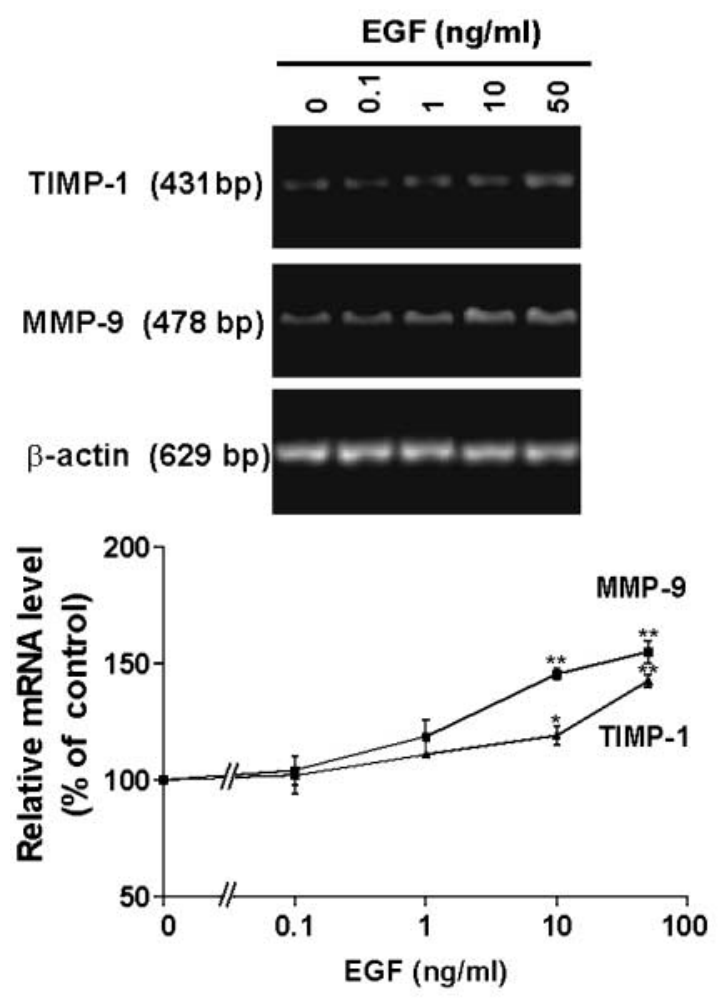

Effect of EGF and inhibitors of PI3K and MAPK on proMMP-9 activity and TIMP-1 content

Culture of trophoblast cells in the presence of EGF resulted in a concentration-dependent increase in the activity of proMMP-9 $(92 \mathrm{kDa})$. In contrast, proMMP-2 activity $(72 \mathrm{kDa})$ remained unchanged irrespective of the concentration of EGF (Fig. 3A).

To examine whether regulation of proMMP-9 activity involves PI3K or MAPK, or both, cells were treated with these specific inhibitors, as described above. In the presence of EGF $(10 \mathrm{ng} / \mathrm{ml})$, treatment with either LY294002 or U0126 markedly reduced the activities of proMMP-9, although the response was more pronounced with the PI3K inhibitor (Fig. 3B). The presence of both inhibitors elicited a greater response compared with that observed with EGF/U0126 treatment, but not with EGF/LY294002 treatment (Fig. 3B).

Western blot analysis of conditioned media after EGF treatment indicated a concentration-dependent increase in the content of TIMP-1, but not of TIMP-2 (Fig. 4A). Pretreatment of trophoblast cells with LY294002 or U0126

B
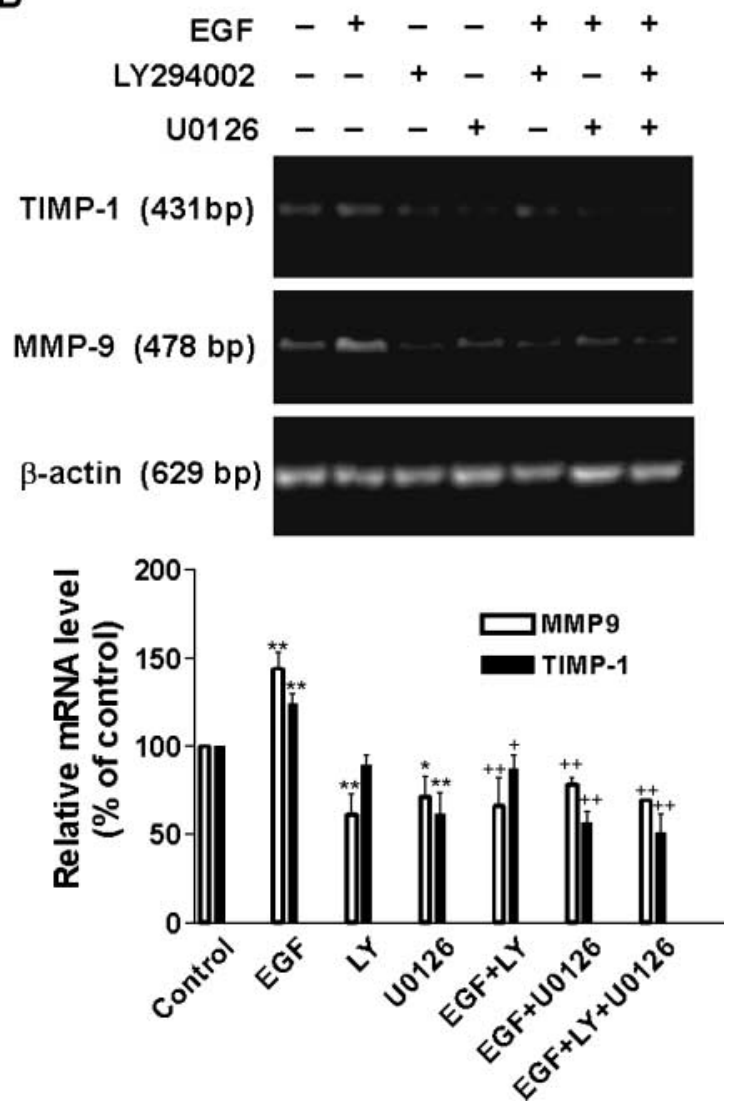

Figure 2 Effect of EGF and inhibitors of PI3K and MAPK on the abundance of MMP-9 and TIMP-1 mRNA. (A) Concentration effect of EGF $(0,0.1,1,10$ and $50 \mathrm{ng} / \mathrm{ml})$ on MMP-9 and TIMP-1 mRNAs after treatment for $24 \mathrm{~h}$. (B) Influence of inhibitors of PI3K (LY294002; LY, 20 $\mu \mathrm{mol} / \mathrm{l})$ and MAPK (U0126, $10 \mu \mathrm{mol} / \mathrm{l})$ on EGF $(10 \mathrm{ng} / \mathrm{ml})$-induced levels of MMP-9 and TIMP-1 mRNAs. Top panels in (A) and (B) show representative results of agrose gel electrophoresis of RT-PCR product, and bottom panels are graphic representations of the relative mRNA levels. The amplification for each gene was in the linear range. Values represent means \pm S.E.M. of three independent experiments. $* P<0.05$ or $* * P<0.01$ compared with control; $+P<0.05,++P<0.01$ compared with EGF alone. 
A
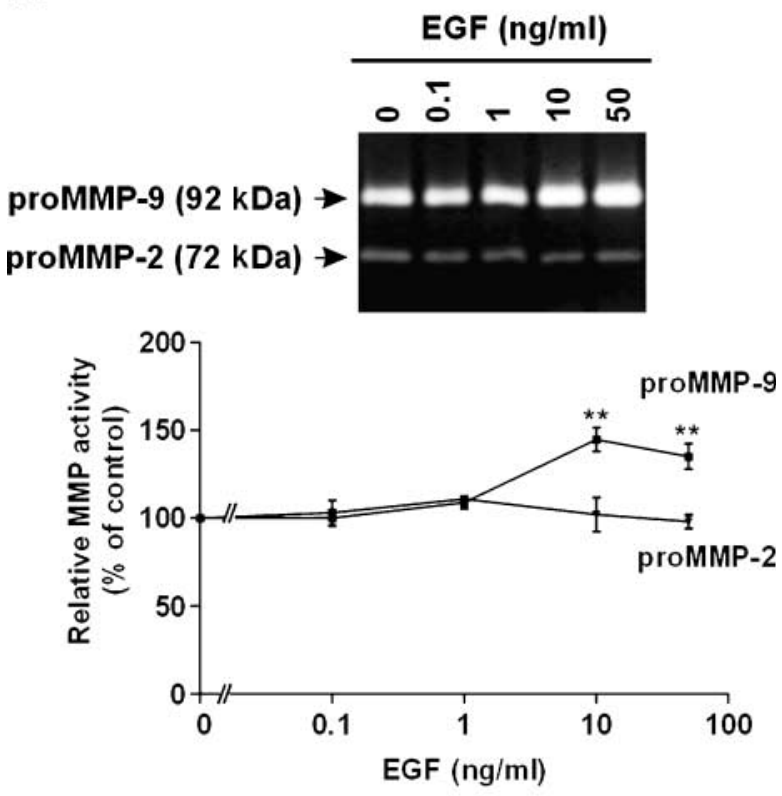

B
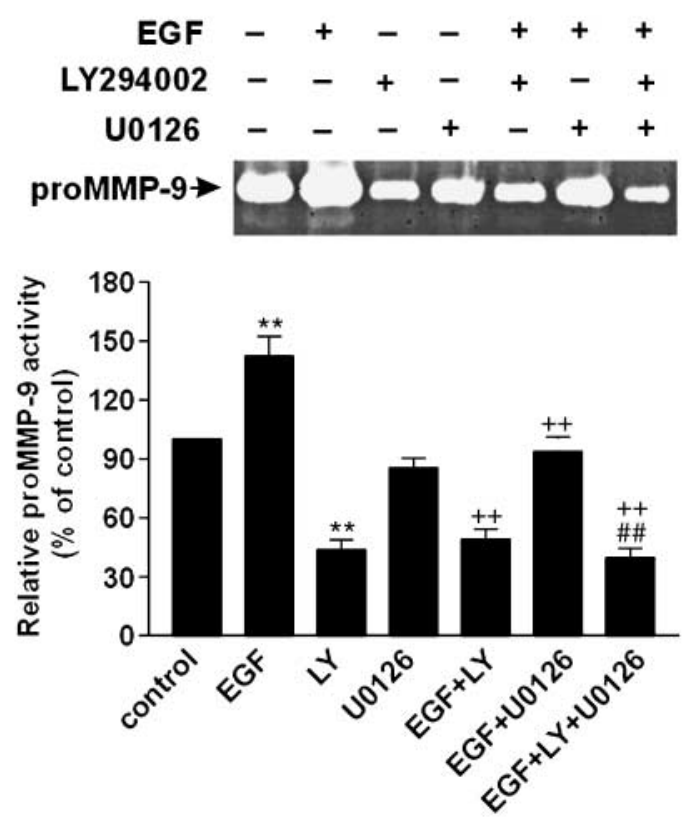

Figure 3 Effect of EGF and inhibitors of PI3K and MAPK on MMP activity. (A) Concentration effect of EGF (0, 0.1, 1, 10 and $50 \mathrm{ng} / \mathrm{ml}$ ) on proMMP-9 and proMMP-2 activity after treatment for $24 \mathrm{~h}$. Top panel: representative proMMP-9 and proMMP-2 zymogram. Bottom panel: graphic representation of relative MMP activity. (B) Influence of inhibitor of PI3K (LY294002; LY, $20 \mu \mathrm{mol} / \mathrm{l})$ and MAPK (U0126, $10 \mu \mathrm{mol} / \mathrm{l})$ on EGF (10 ng/ml)-induced secretion of MMP-9. Top panel: representative proMMP-9 zymogram. Bottom panel: graphic representation of relative proMMP-9 activity. The values are the means \pm S.E.M. of three independent experiments. $P<0.01$ : **compared with control, ++ compared with EGF alone, \#\#compared with EGF+U0126. decreased both basal and EGF-induced TIMP-1 protein content. In the presence of both inhibitors, TIMP-1 secretion was completely suppressed. The inhibitors failed to alter TIMP-2 protein content in the trophoblast cells (Fig. 4B).

\section{Effect of Akt activation on proMMP-9 and TIMP-1 secretion}

The influence of Akt activation on the secretion of MMP-9 and TIMP-1 was examined by investigating their content in spent media after the expression of three constitutively active Akt isoforms (Myr-Akt1, Myr-Akt2 and Myr-Akt3). All three Akt isoforms were highly expressed and phosphorylated in whole cell lysate as detected by an immunoblotting assay with HA-Akt and phospho-Akt antibody respectively (Fig. 5A). In order to determine whether expressed active Akt forms were functional or not, an Akt downstream target, phosphorylation of p70S6K $\left(\mathrm{Thr}^{389}\right)$, was examined. Although the expression of all active Akt forms increased phospho-p70S6K $\left(\mathrm{Thr}^{389}\right)$ content, none of them had any effects on proMMP-9 activities (Fig. 5B) and TIMP-1 protein content (Fig. 5C) in the conditioned media.

\section{Discussion}

The ability of a stimulus to induce MMP-9 expression is dependent on the integration of specific signal transduction pathways, which leads to cell type specific and stimulus specific activation of the MMP-9 gene. For instance, phorbol 12-myristate 13-acetate (PMA)-induced expression of MMP-9 in tumour cells has been reported to be mediated through p38MAPK activation (Simon et al. 2001). However, in endothelial cells the classical mitogenic Raf/MEK/ERK cascade, but not the p38MAPK pathway, is responsible for PMA-induced MMP-9 expression (Genersch et al. 2000, Park et al. 2003). Protein kinase (PKC) is involved in the up-regulation of MMP-9 gene transcription by $\mathrm{TNF} \alpha$ in glioma cells (Esteve et al. 2002a), whereas TNF $\alpha$-induced MMP-9 secretion is upregulated through Raf/MEK/ERK cascade and PKC is not involved in endothelial cells (Genersch et al. 2000). The roles of PI3K-dependent signalling in the regulation of MMP-9 expression are not consistent in various cell types (Esparza et al. 1999, Thant et al. 2000, Esteve et al. $2002 b$ ). In the present studies, we have shown that EGF activates both PI3K and MAPK pathways, leading to the up-regulation of MMP-9 in this trophoblast cell line. Both PI3K inhibitor and MAPK inhibitor, alone or in combination, blocked EGF-induced expression of MMP-9 (Figs 2B, 3B), suggesting that MMP-9 transcriptional activation may require the cooperation of two or more transcription factors activated by distinct signalling transduction pathways. It remains to be determined whether these signalling pathways further activate $\mathrm{NF \kappa B}$ (Bancroft et al. 2002) and AP-1 (Gum et al. 1997) respectively and whether activation of these transcription factors 
promotes MMP-9 gene transcription (Huhtala et al. 1991), both of which have been demonstrated in other cell types. Our results are consistent with the reports that both PI3K/Akt and MAPK/ERK are essential signals for activation of MMP-9 transcription by fibronectin in ovarian

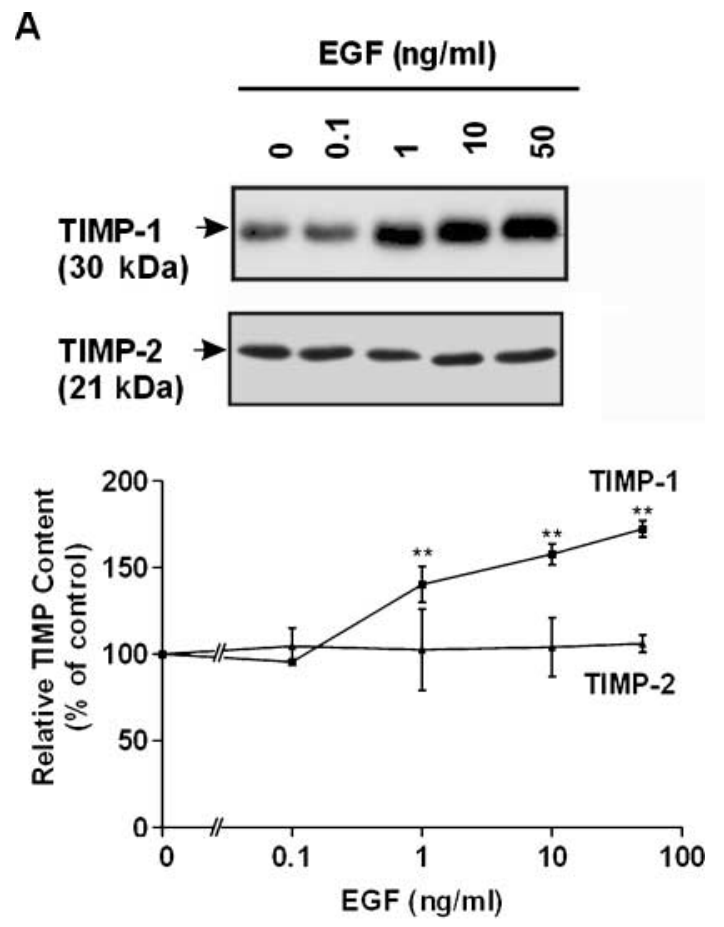

B
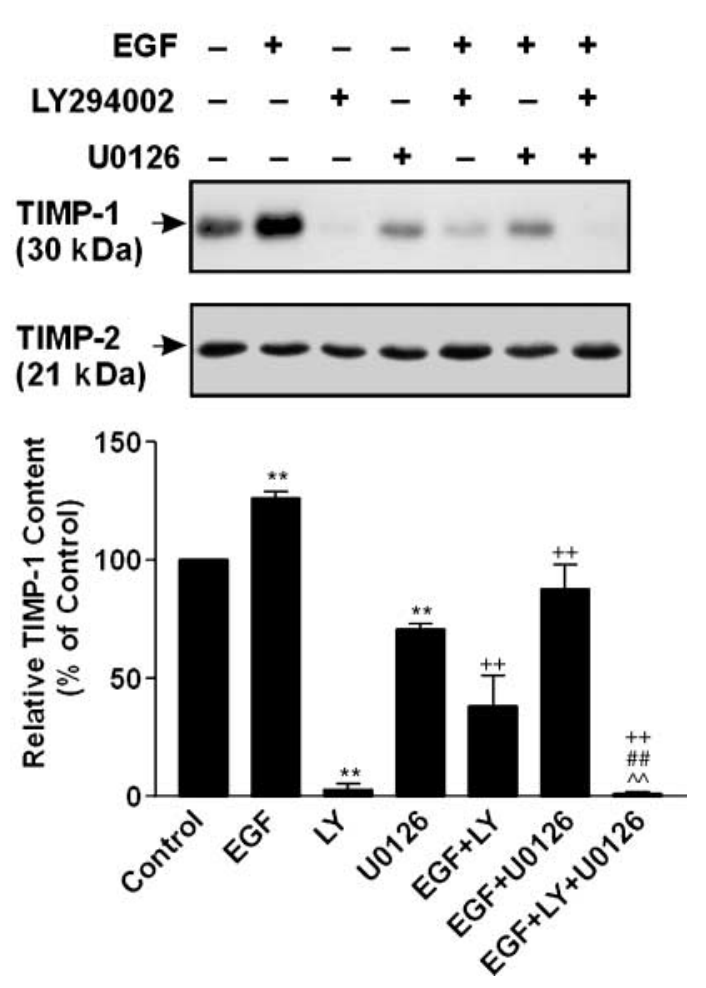

cancer cells (Thant et al. 2000) and IL-1 $\beta$ in a mouse fibroblast cell line (Ruhul Amin et al. 2003).

Although MMP-2 and MMP-9 have similar substrate specificities, differences exist in their expression in response to EGF. Consistent with other reports in various other cell lines (Charoenrat et al. 2000, Liu \& Klominek 2003, Nutt et al. 2003), our results showed that EGF stimulates secretion of proMMP-9 but not of proMMP-2 (Fig. 3A). It has also been shown that IL-1 $\alpha$, leptin, 12-otetradecanoylphorbol 13-acetate (TPA) and TNF $\alpha$ up-regulate MMP-9 expression but have no effect on MMP-2 activity in human cytotrophoblasts (Gonzalez et al. 2001,

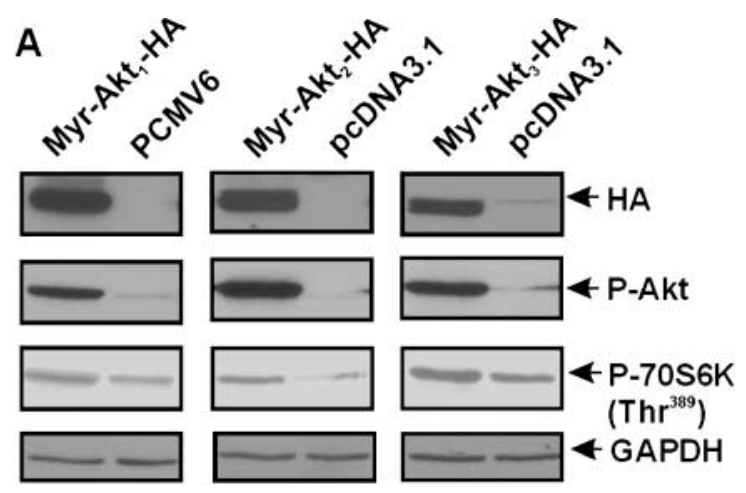

B

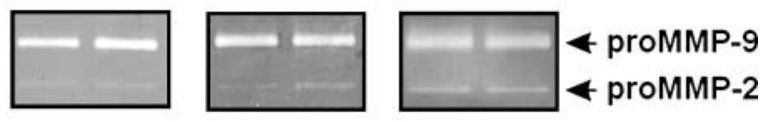

C

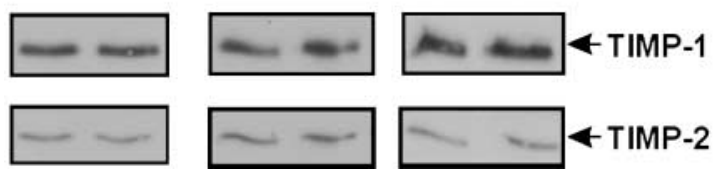

Figure 5 Expression of a constitutively active Akt (Myr-Akt1, Myr-Akt2 and Myr-Akt3) is not sufficient to induce secretion of proMMP-9 and TIMP-1. HTR8/SVneo cells were transiently transfected with MyrAkt1, Myr-Akt2 and Myr-Akt3 or their parent vectors for $6 \mathrm{~h}$ and incubated in fresh medium without serum for $18 \mathrm{~h}$. (A) Protein contents of HA-Akt (HA), P-Akt, P-P70S6K $\left(\mathrm{Thr}^{389}\right.$ ) and GAPDH were detected in whole cell lysate by immunoblotting. (B) Zymographic analysis of proMMP-9 and proMMP-2 activity in conditioned media. (C) Western blot analysis of protein content of TIMP-1 and TIMP-2 in conditioned media.

Figure 4 Effect of EGF and inhibitors of PI3K and MAPK on TIMP-1 and TIMP-2 protein content. (A) Concentration-dependent effects of $\operatorname{EGF}(0,0.1,1,10$ and $50 \mathrm{ng} / \mathrm{ml})$ on TIMP-1 and TIMP-2 protein contents after treatment for $24 \mathrm{~h}$. (B) Influence of inhibitors of PI3K (LY294002; LY, $20 \mu \mathrm{mol} / \mathrm{l}$ ) and MAPK (U0126, $10 \mu \mathrm{mol} / \mathrm{l}$ ) on EGF $(10 \mathrm{ng} / \mathrm{ml})$-induced secretion of TIMP-1 and TIMP-2. Contents of TIMPs were determined with Western blot in condensed media. The values are the means \pm S.E.M. of three independent experiments. $P<0.01$ : **compared with control, ++ compared with EGF alone, \#\#compared with EGF+U0126), ^^compared with EGF+LY294002. 
Bischof et al. 2003), possibly because of the presence of different promoter elements on the gelatinase genes (Huhtala et al. 1991).

The functional activity of MMP-9 is dependent on the relative abundance of the protease and its natural inhibitor, TIMP-1. In the present study, we have shown that both TIMP-1 and MMP-9 are up-regulated in a similar fashion after EGFR activation. These findings could be explained by the fact that the promoter of MMP-9 and TIMP-1 contains AP-1 and Ets binding sites (Borden \& Heller 1997) and these transcription factors can be activated by EGF (Watabe et al. 1998, Li et al. 2003). As both Ets and AP-1 families are required to control TIMP-1 gene expression, it has been suggested that TIMP-1 expression may be regulated through the co-ordination of several signal transduction pathways (Logan et al. 1996). Indeed, our current studies have shown that both PI3K and MAPK signalling pathways are involved in the regulation of TIMP-1 expression in HTR8/SVneo cells.

Although our current observation of a concomitant upregulation of MMP-9 and TIMP-1 by EGF may appear physiologically contradictory, this may be explained by the multifunctional properties of TIMP-1. It is possible that the up-regulation of the inhibitor is necessary to prevent excessive trophoblast invasion and to ensure normal placental development. Alternatively, the capacity of TIMP-1 to inactivate MMP-9 may be attenuated by other extracellular proteases present in the microenvironment of the trophoblast. For instance, leucocyte elastase has been shown to inactivate TIMP-1 while allowing the conversion of proMMP-9 to its catalytically active form (Itoh \& Nagase 1995). In addition, TIMPs may serve other cellular functions in addition to MMP-9 regulation, including control of cell growth and differentiation and programmed cell death (Guedez et al. 1998, Li et al. 1999), although the mechanism involved remains to be elucidated.

Akt activation is one of the major downstream events of $\mathrm{PI3K}$ signalling. Three mammalian isoforms (Akt1/PKB $\alpha$, $\mathrm{Akt} 2 / \mathrm{PKB} \beta$ and $\mathrm{Akt} 3 / \mathrm{PKB} \gamma$ ) have been identified (Chan et al. 1999) and, despite a high degree of structural identity and a similar activation process, they appear to have distinct physiological roles (Cho et al. 2001) and a tissuespecific pattern of expression (Brodbeck et al. 1999, Nakatani et al. 1999). To investigate if Akt activation alone can up-regulate the expression of MMP-9 and TIMP-1, we have examined in the present studies whether the expression of the three constitutively active Akt forms (Myr-Akt1, Myr-Akt2 and Myr-Akt3) would increase their expression. Although the contents of phospho-Akt and phospho-p70S6K $\left(\mathrm{Thr}^{389}\right.$ ) (a downstream target of Akt) increased in all three experimental groups (Fig. 5A), they were ineffective in altering the secretion of proMMP-9 and TIMP-1, suggesting that activation of Akt by itself is not sufficient for the induction of these proteins and again leading support to the contention that more than one signalling pathway is necessary for proMMP-9 and TIMP-1 secretion in HTR8/SVneo cells.
In the present study, LY294002 or U0126 alone appeared to suppress the expression of MMP-9 and TIMP-1 relative to control. This could not be attributable to the overall cytotoxic effects of the kinase inhibitor, because MMP-2 activity (data not shown) and TIMP-2 protein contents (Fig. 4B), in addition to the abundance of $\beta$-actin mRNA, were unaffected. Alternatively, it is possible that the observed changes in 'basal' parameters reflect suppression by the inhibitors of the PI3K/Akt or MAPK signalling pathway activated by an endogenous autocrine factor (e.g. EGF or IGF-II) secreted by the trophoblast cells during the culture period.

In conclusion, we have demonstrated that EGF stimulation increases the abundance of MMP-9/TIMP-1 mRNA and proMMP-9 activity, in addition to TIMP-1 protein content, in HTR8/SVneo cells. Both PI3K/Akt and MAPK/ERK signalling are essential to regulate the expression of MMP9 and TIMP- 1 by EGF in HTR8/SVneo cells. Increased MMP-9 and TIMP-1 expression induced by EGF involve the co-ordinated regulation of both PI3K and MAPK signalling pathways.

\section{Acknowledgements}

This work was supported by a grant from the Philip Morris Inc. external research programme. We thank Dr Charles Graham (Department of Anatomy and Cell biology, Queen's University, Kingston, Ontario, Canada L7L 3N6) for the gift of HTR8/SVneo cell line and Dr Jin Cheng (University of South Florida, Tampa, Florida, USA) who generously provided constitutively active Akt vectors.

\section{References}

Bancroft C, Chen Z, Yeh J, Sunwoo J, Yeh N, Jackson S, Jackson C \& Van Waes C 2002 Effects of pharmacologic antagonists of epidermal growth factor receptor, PI3K and MEK signal kinases on NF-kappaB and AP-1 activation and IL-8 and VEGF expression in human head and neck squamous cell carcinoma lines. International Journal of Cancer 99 538-548.

Bass K, Morrish D, Roth I, Bhardwaj D, Taylor R, Zhou Y \& Fisher S 1994 Human cytotrophoblast invasion is up-regulated by epidermal growth factor: evidence that paracrine factors modify this process. Developmental Biology 164 550-561.

Behrendtsen O, Alexander C \& Werb Z 1992 Metalloproteinases mediate extracellular matrix degradation by cells from mouse blastocyst outgrowths. Development 114 447-456.

Bischof P, Meisser A, Campana A \& Tseng L 1998 Effects of deciduaconditioned medium and insulin-like growth factor binding protein-1 on trophoblastic matrix metalloproteinases and their inhibitors. Placenta 19 457-464.

Bischof P, Meisser A \& Campana A 2002 Control of MMP-9 expression at the maternal-fetal interface. Journal of Reproductive Immunology 55 3-10.

Bischof P, Truong K \& Campana A 2003 Regulation of trophoblastic gelatinases by proto-oncogenes. Placenta 24 155-163.

Borden P \& Heller R 1997 Transcriptional control of matrix metalloproteinases and the tissue inhibitors of matrix metalloproteinases. Critical Reviews in Eukaryotic Gene Expression 7 159-178.

Brodbeck D, Cron P \& Hemmings B 1999 A human protein kinase Bgamma with regulatory phosphorylation sites in the activation 
loop and in the C-terminal hydrophobic domain. Journal of Biological Chemistry 274 9133-9136.

Campbell S, Rowe J, Jackson C \& Gallery E 2003 In vitro migration of cytotrophoblasts through a decidual endothelial cell monolayer: the role of matrix metalloproteinases. Placenta 24 306-315.

Castellucci M, De Matteis R, Meisser A, Cancello R, Monsurro V, Islami D, Sarzani R, Marzioni D, Cinti S \& Bischof P 2000 Leptin modulates extracellular matrix molecules and metalloproteinases: possible implications for trophoblast invasion. Molecular Human Reproduction 6 951-958.

Chan T, Rittenhouse S \& Tsichlis P 1999 AKT/PKB and other D3 phosphoinositide-regulated kinases: kinase activation by phosphoinositide-dependent phosphorylation. Annual Review of Biochemistry 68 965-1014.

Charoenrat P, Modjtahedi H, Rhys-Evans P, Court W, Box G \& Eccles S 2000 Epidermal growth factor-like ligands differentially up-regulate matrix metalloproteinase 9 in head and neck squamous carcinoma cells. Cancer Research 60 1121-1128.

Cho H, Mu J, Kim J, Thorvaldsen J, Chu Q, Crenshaw E III, Kaestner K, Bartolomei M, Shulman G \& Birnbaum M 2001 Insulin resistance and a diabetes mellitus-like syndrome in mice lacking the protein kinase Akt2 (PKB beta). Science 292 1728-1731.

Cox G, Jones J \& O'Byrne K 2000 Matrix metalloproteinase 9 and the epidermal growth factor signal pathway in operable non-small cell lung cancer. Clinical Cancer Research 6 2349-2355.

Denhardt D, Feng B, Edwards D, Cocuzzi E \& Malyankar U 1993 Tissue inhibitor of metalloproteinases (TIMP, aka EPA): structure, control of expression and biological functions. Pharmacology and Therapeutics 59 329-341.

Dubois B, Arnold B \& Opdenakker G 2000 Gelatinase B deficiency impairs reproduction. Journal of Clinical Investigation $\mathbf{1 0 6}$ 627-628.

Ellerbroek S, Hudson L \& Stack M 1998 Proteinase requirements of epidermal growth factor-induced ovarian cancer cell invasion. International Journal of Cancer 78 331-337.

Esparza J, Vilardell C, Calvo J, Juan M, Vives J, Urbano-Marquez A, Yague J \& Cid M 1999 Fibronectin upregulates gelatinase B (MMP-9) and induces coordinated expression of gelatinase A (MMP-2) and its activator MT1-MMP (MMP-14) by human T lymphocyte cell lines. A process repressed through RAS/MAP kinase signaling pathways. Blood 94 2754-2766.

Esteve P, Chicoine E, Robledo O, Aoudjit F, Descoteaux A, Potworowski E \& St Pierre Y 2002a Protein kinase C-zeta regulates transcription of the matrix metalloproteinase- 9 gene induced by IL-1 and TNF-alpha in glioma cells via NF-kappa B. Journal of Biological Chemistry 277 35150-35155.

Esteve P, Robledo O, Potworowski E \& St Pierre Y 2002b Induced expression of MMP-9 in C6 glioma cells is inhibited by PDGF via a PI 3-kinase-dependent pathway. Biochemical and Biophysical Research Communications 296 864-869.

Genersch E, Hayess K, Neuenfeld Y \& Haller H 2000 Sustained ERK phosphorylation is necessary but not sufficient for MMP-9 regulation in endothelial cells: involvement of Ras-dependent and -independent pathways. Journal of Cell Science 113 4319-4330.

Gonzalez R, Devoto L, Campana A \& Bischof P 2001 Effects of leptin, interleukin-1alpha, interleukin-6, and transforming growth factor-beta on markers of trophoblast invasive phenotype: integrins and metalloproteinases. Endocrine 15 157-164.

Graham C, Hawley T, Hawley R, MacDougall J, Kerbel R, Khoo N \& Lala P 1993 Establishment and characterization of first trimester human trophoblast cells with extended lifespan. Experimental Cell Research 206 204-211.

Guedez L, Stetler-Stevenson W, Wolff L, Wang J, Fukushima P, Mansoor A \& Stetler-Stevenson M 1998 In vitro suppression of programmed cell death of B cells by tissue inhibitor of metalloproteinases-1. Journal of Clinical Investigation $\mathbf{1 0 2}$ $2002-2010$.
Gum R, Wang H, Lengyel E, Juarez J \& Boyd D 1997 Regulation of $92 \mathrm{kDa}$ type IV collagenase expression by the jun aminoterminal kinase- and the extracellular signal-regulated kinase-dependent signaling cascades. Oncogene 14 1481-1493.

Huhtala P, Tuuttila A, Chow L, Lohi J, Keski-Oja J \& Tryggvason K 1991 Complete structure of the human gene for 92-kDa type IV collagenase. Divergent regulation of expression for the 92- and 72kilodalton enzyme genes in HT-1080 cells. Journal of Biological Chemistry 266 16485-16490.

Itoh Y \& Nagase H 1995 Preferential inactivation of tissue inhibitor of metalloproteinases-1 that is bound to the precursor of matrix metalloproteinase 9 (progelatinase B) by human neutrophil elastase. Journal of Biological Chemistry 270 16518-16521.

Kolben M, Lopens A, Blaser J, Ulm K, Schmitt M, Schneider K \& Tschesche H 1996 Proteases and their inhibitors are indicative in gestational disease. European Journal of Obstetrics, Gynecology, and Reproductive Biology 68 59-65.

Li G, Fridman R \& Kim H 1999 Tissue inhibitor of metalloproteinase-1 inhibits apoptosis of human breast epithelial cells. Cancer Research 59 6267-6275.

Li J, Ma C, Huang Y, Luo J \& Huang C 2003 Differential requirement of EGF receptor and its tyrosine kinase for AP-1 transactivation induced by EGF and TPA. Oncogene 22 211-219.

Librach C, Feigenbaum S, Bass K, Cui T, Verastas N, Sadovsky Y, Quigley J, French D \& Fisher S 1994 Interleukin-1 beta regulates human cytotrophoblast metalloproteinase activity and invasion in vitro. Journal of Biological Chemistry 269 17125-17131.

Licht P, Russu V \& Wildt L 2001 On the role of human chorionic gonadotropin (hCG) in the embryo-endometrial microenvironment: implications for differentiation and implantation. Seminars in Reproductive Medicine 19 37-47.

Liu Z \& Klominek J 2003 Regulation of matrix metalloprotease activity in malignant mesothelioma cell lines by growth factors. Thorax 58 198-203.

Logan S, Garabedian M, Campbell C \& Werb Z 1996 Synergistic transcriptional activation of the tissue inhibitor of metalloproteinases-1 promoter via functional interaction of AP-1 and Ets-1 transcription factors. Journal of Biological Chemistry 271 774-782.

Meisser A, Chardonnens D, Campana A \& Bischof P 1999 Effects of tumour necrosis factor-alpha, interleukin-1 alpha, macrophage colony stimulating factor and transforming growth factor beta on trophoblastic matrix metalloproteinases. Molecular Human Reproduction 5 252-260.

Nakatani K, Sakaue H, Thompson D, Weigel R \& Roth R 1999 Identification of a human Akt3 (protein kinase B gamma) which contains the regulatory serine phosphorylation site. Biochemical and Biophysical Research Communications 257 906-910.

Nutt J, Durkan G, Mellon J \& Lunec J 2003 Matrix metalloproteinases (MMPs) in bladder cancer: the induction of MMP9 by epidermal growth factor and its detection in urine. BJU International 91 99-104.

Park M, Park I, Lee H, Woo S, Lee J, Hong Y, Rhee C, Lee Y, Lee S, Shim B, Kuroki T \& Hong S 2003 Protein kinase C-alpha activation by phorbol ester induces secretion of gelatinase B/MMP-9 through ERK $1 / 2$ pathway in capillary endothelial cells. International Journal of Oncology 22 137-143.

Roth I \& Fisher S 1999 IL-10 is an autocrine inhibitor of human placental cytotrophoblast MMP-9 production and invasion. Developmental Biology 205 194-204.

Ruhul Amin A, Senga T, Oo M, Thant A \& Hamaguchi M 2003 Secretion of matrix metalloproteinase-9 by the proinflammatory cytokine, IL-1 beta: a role for the dual signalling pathways, Akt and Erk. Genes Cells 8 515-523.

Simon C, Simon M, Vucelic G, Hicks M, Plinkert P, Koitschev A \& Zenner H 2001 The p38 SAPK pathway regulates the expression of 
the MMP-9 collagenase via AP-1-dependent promoter activation. Experimental Cell Research 271 344-355.

Thant A, Nawa A, Kikkawa F, Ichigotani Y, Zhang Y, Sein T, Amin A \& Hamaguchi M 2000 Fibronectin activates matrix metalloproteinase-9 secretion via the MEK1-MAPK and the PI3K-Akt pathways in ovarian cancer cells. Clinical and Experimental Metastasis 18 423-428.

Van den Steen P, Dubois B, Nelissen I, Rudd P, Dwek R

\& Opdenakker G 2002 Biochemistry and molecular biology of gelatinase B or matrix metalloproteinase-9 (MMP-9). Critical Reviews in Biochemistry and Molecular Biology 37 375-536.
Watabe T, Yoshida K, Shindoh M, Kaya M, Fujikawa K, Sato H, Seiki M, Ishii S \& Fujinaga K 1998 The Ets-1 and Ets-2 transcription factors activate the promoters for invasion-associated urokinase and collagenase genes in response to epidermal growth factor. International Journal of Cancer 77 128-137.

Received 14 March 2004

First decision 23 April 2004

Accepted 8 June 2004 